\title{
MATERIALES PARA EL ESTUDIO DE LAS ELECCIONES GENERALES DE 1986 EN BALEARES
}

JOAN OLIVER ARAUJO 
Revista" de Derecho Político, núm. 23, 1986, pp. 209-244

\section{MATERIALES PARA EL ESTUDIO DE LOS PARLAMENTOS}

(III)

POR

ROSARIO HERRERO GUTIERREZ

\section{ITALIA}

\section{Publicaciones Parlamentarias}

Los Atti parlamentari, actos y documentos, han sufrido modificaciones en su denominación, series, etc. a lo largo de su historia parlamentaria. Es fácil seguir su evolución a través de una colección muy completa que la Camera dei Deputati ha publicado, y que abarca desde 1848 a la actualidad. Comprende:

1. Atti del parlamento subalpino * (1848-1860), legislaturas: I a VII. Se compone de dos grandes series: Documenti y Discussioni. La primera, común para ambas Cámaras; la segunda, independiente.

a) Documenti della Camera e del Senato (dissegni di legge, relazioni, etcétera).

b) Discussioni della Camera di Deputati.

c) Discussioni del Senato del Regno, (66 volúmenes).

2. Atti del Parlamento Italiano/Atti Parlamentari (1860-1939). Legislaturas VIII a XIX:

Desde el año 1860 a 1865 (Legislatura VIII) sigue denominándose igualmente Documenti della Camera e del Senato; Discussioni della Camera dei Deputati y Discussioni del Senato del Regno (44 volúmenes).

A partir de 1865 (Legislatura IX) hasta 1874 (Legislatura XII): Camera dei

NOTA: Este trabajo (partes I, II, III), fue realizado en 1983. Las partes I y II se han publicado en los números $18-19$, y 22 , respectivamente, de esta Revista. La II y la que ahora sale a la luz, no han podido ser puestas al día por circunstancias ajenas a la voluntad de la autora, lo que si no hace perder el interés del trabajo, puede resultar en algún punto carente de la actualidad deseada.

* Las tres primeras legislaturas del Parlamento subalpino fueron semipúblicas, recogiéndose en la Gazzeta Piemontese. A partir de 1848 se publicó en forma de suplemento, con paginación propia, dividida en 2 partes: una para la Camera y otra para el Senato. A partir de 1856 se publicó una edición en $4 .^{\circ}$, denominada Ristanina. 
Deputati: Dissegni di legge - Relazioni - Documenti. Camera dei Deputati Discussioni. Senato del Regno: Discussioni (87 volúmenes).

Desde 1874 (Legislatura XII) las publicaciones de las Cámaras son independientes, y a partir de 1878 (Legislatura XIII), la parte "Documenti" se divide en dos series: biga).

Camera dei Deputati: Dissegni di legge-Relazioni (con numeración ará-

Camera dei Deputati: Documenti (con numeración romana.)

Camera dei Deputati: Discussioni.

Senato: Dissegni di legge.

Senato. Documenti.

Senato. Discussioni.

(El número de volúmenes de la Colección de Documentación parlamentaria de la Camera dei Deputati desde 1860 a 1939 , es de 803.)

3. Legislatura XXX (1939-1943)

- Camera dei Fasci e delle Corporazioni: Dissegni di legge-relazioni.

- Camera dei Fasci e delle Corporazioni: Documenti.

- Camera dei Fasci e delle Corporazioni: Discussioni.

4. Consulta Nazionale (1945-1946)

- Documenti

- Discussioni.

5. Assemblea Costituente (1946-1948)

a) Dissegni di legge -Relazioni-Documenti.

b) Discussioni.

(Los trabajos preparativos sobre la Constitución se publicaron aparte:

- Atti della Commissione per la Costituzione.

- Atti della Assemblea Costituente.

- La Costituzione della Republica nei lavori preparatori dell'Assemblea Costituente, [Roma, stabilimenti tipografici Carlo Colombo, 1971]).

6. Legislatura (1948-1953) a VIII Legislatura (1979/...)

Como veremos, las publicaciones parlamentarias italianas, en la actualidad comprenden: Documenti "Disegni e proposte di legge-relatione" (informes de comisiones), Diarios de sesiones plenarias y Diarios de sesiones de comisiones.

\subsection{Camera dei Deputati}

- Camera dei Deputati. Disegni e proposte di Legge-Relazioni.

Comprende la colección de "disegni» de leyes, proposiciones de ley, proposiciones de "legge costituzionale" y las ponencias correspondientes. Están nume- 
radas correlativamente con números arábigos. Para cada legislatura la numeración es correlativa. Los documentos a que se refieren las proposiciones o proyectos de ley hacen constar la sesión plenaria en que se presentó; asimismo se refleja en los «resoconti».

\section{- Camera dei Deputati. Documenti-Relazioni.}

Colección de «Messaggi del Presidente della Republica»; «Proposte di modifica al Regolamento"; "Domande di Autorizzazione a procedere»; "Bilanci Interni della Camera»; "Relazioni della Corte dei Conti». Cada categoría está ordenada con numeración romana (I, II, III); dentro de esta categoria se sigue numeración correlativa. Para alguna categoria hay clasificación diversa dentro de cada Cámara.

\section{- Camera dei Deputati. Atti Parlamentari dell'Assemblea-Discussioni.}

Comprende la reproducción taquigráfica resoconti stenografico, de los debates de las sesiones de la Asamblea. Tiene paginación progresiva para toda la legislatura. Cada volumen contiene índice. (Se publica simultáneamente al «resoconto sommarì una edición no definitiva taquigráfica, posteriormente se publica el definitivo y se pone a la venta del público).

\section{- Camera dei Deputati. Atti Parlamentari - Discussione delle Comissioni in sede legislativa.}

Colección de los debates taquigráficos de las sesiones de las Comisiones. Cada volumen recoge los debates de una Comisión con un índice por legislatura.

\section{- Camera dei Deputati. Atti Parlamentari - Bilancio dello Stato. Esame in sede consultiva presso le Commissioni permanenti.}

Comprende: colección de debates taquigráticos de las sesiones de las comisiones permanentes relativas al examen para posterior toma en consideración por la Comisión de Presupuestos sobre el «Disegni di legge» referente al presupuesto del Estado. Cada Comisión tiene paginación correlativa (en la actualidad no hay indice general).

\section{- Camera dei Deputati. Atti Parlamentari - Risposte scritte ad interroga- zioni.}

Contiene los fascículos adjuntos a los debates de las sesiones en las cuales se han presentado respuestas escritas. Cada fascículo comprende el índice y lista alfabética de las preguntas presentadas, de las que se han dado respuesta y que se publica a continuación. La paginación es correlativa para la legislatura. Cada volumen contiene un índice del fascículo.

\section{- Camera dei Deputati. Resoconto Sommario.}

Recoge la información más rápida y concisa de los debates de las sesiones. Están a disposición de la prensa en el curso mismo de la Sesión. Su ordenación es cronológica y cada «Resoconto» posee su propio índice y paginación. Las mociones, interpelaciones, preguntas y resoluciones presentadas en la sesión de referencia, tienen paginación distinta con números romanos.

La Camera dei Deputati ha publicado una colección de Resoconto Sommari de los años 1950-1957 y 1965-1972. 
- Camera dei Deputati. Bolletino delle Giunte e delle Commissioni Parlamentari.

Comenzó a publicarse en 1948 con el título de Bollettino delle Commissioni. En la Camera dei Deputati fue una misma publicación con el uresoconto sommario" desde 1950 a 1957; pero a partir de 1958 se imprime como publicación independiente. (La Camera dei Deputati ha publicado una colección desde 1948 a 1972 de 37 volúmenes).

El Bollettino es una colección cronológica de los «resoconti sommari» de las sesiones «delle Giunte e delle Commissioni permanentti» y "Speciali» en «sede legislativa, consultiva e referente". También contiene noticias relacionadas con la actividad de estos órganos de la Cámara: convocatorias, "Comitati pareri", etcétera. Cada resoconto contiene índice.

Finalmente:

- Camera dei Deputati - Senato della Republica. Atti parlamentari delle Sedute Comuni.

Colección de las sesiones taquigráficas de la sesión del Parlamento en sesión conjunta. Tiene paginación varia e índice en cada volumen.

Los servicios de documentación automatizada de las Cámaras proporcionan datos concernientes al procedimiento parlamentario de formación de las leyes; se puede localizar por número, materia, autor, grupo parlamentario, etc. las interpelaciones, mociones, preguntas, órdenes del día del Senato o Camera dei Deputati, obtener información sobre datos estadísticos de la actividad parlamentaria, etc.

Algunas guías muy útiles de la actividad parlamentaria y legislativa de las Cámaras, son:

- Indice alfabético per autori delle relazioni sui disegni di legge e sulla proposte presentata al Senato ed alla Camera dei Deputati del 1848 al 1882 (Roma, 1883).

- Indice generale degli Atti parlamentari, 1848-1897 (publicado por la Camera dei Deputati).

- Indice alfabético dell'attivitá svolta dai parlamentari della I Legislatura alla Camera dei Deputati.

Indice general de la actividad de cada diputado en el censo de la legislatura. Incluye, además, tres apéndices con datos y noticias sobre el Gobierno y la Cámara, así como sobre la actividad de la Asamblea relativa a determinadas materias como Presupuestos internos, conmemoraciones, dimisiones, etc.

\subsection{Senato}

Por su parte, el Senado publica igualmente los documentos y discusiones parlamentarias:

- Senato. Disegni di legge.

- Senato. Atti parlamentari del Senato. Discussioni (Resoconto stenografico). 
- Senato. Resoconto Sommario.

- Senato. Documenti.

- Senato. Risposte scritti ad interrogazioni giunte e Commissioni parlamentari.

De la documentación del Senato destacamos alguna particularidad:

a) Los índices de la documentación parlamentaria del Senato. A diferencia de la Camera dei Deputati, son por años.

b) La relación de las Comisiones tienen el mismo número referente a la Cámera seguido de la letra A. Cuando es aprobada en una Cámara y va a la otra, recibe un número nuevo. Si se modifica, volviendo a la cámara de origen, vuelve a tener el número viejo con la letra $B$.

\section{Reglamentos}

Los reglamentos parlamentarios "generali» están publicados en la Gazzetta Ufficiale (Ed. 1971, n. ${ }^{\circ} 53 ; 1977, n .{ }^{\circ} 21$, etc.)

También se publican en la Gazzetta Ufficiale los reglamentos «particolari» o internos (Comisión parlamentaria para el «indirizzo" general y la vigilancia de los servicios de radiotelevisión) (n. ${ }^{\circ} 303$ de 17 de noviembre 1975, etc.).

Los otros reglamentos internos de la Cámara están en publicaciones de ámbito parlamentario, como la colección de L. Elia-G. Guarino, Codice Costituzionale della Repubblica italiana. Milano, 1974; y publicados por las propias Cámaras*.

Los principales reglamentos están recogidos en las colecciones de leyes relativas a la actividad parlamentaria como es el caso del Manuale parlamentare della Camera dei Deputati e Senato, publicado al comienzo de cada legislatura.

El Manuale ha sido publicado alternativamente por la Camera y el Senato, variando su título a lo largo de la historia:

- Manuale ad uso dei senatori del Regno e dei deputati, Roma tipografia Botta, publicado desde 1860 a 1882 (Legislatura VIII, Ed. 1860; Apéndice 1865 Legislatura IX, Ed. 1867; Legislatura X, Ed. 1870; Legislatura XI, Ed. 1873; Legislatura XII, Ed. 1874; Legislatura XIII, Ed. 1876; Legislatura XIV, Ed. 1880; Legislatura XV, 1882).

- Manuale ad uso dei deputati del Parlamento nazionale, Roma, Camera del Deputati, 1886/1921. Comprende las Legislaturas XVI a XXVI: Leg. ${ }^{a}$ XVI, Ed. 1886; Leg. ${ }^{a}$ XVII, Ed. 1890; LEg. ${ }^{a}$ XVIII, Ed. 1892; Leg. ${ }^{a}$ XIX, Ed. 1895; Leg. ${ }^{a}$ XX, Ed. 1897; Leg. ${ }^{a}$ XXI, Ed. 1900; Leg. ${ }^{a}$ XXII, Ed. 1904; Leg. $^{a}$ XXIII, Ed. 1909; Leg. ${ }^{a}$ XXIV, Ed. 1913; Leg. ${ }^{a}$ XXV, Ed. 1919; Leg. ${ }^{a}$ XXVI, Ed. 1921.

* En España el Congreso de los Diputados recoge los Reglamentos de las Cámaras extranjeras en su publicación, Boletín de Legislación Extranjera. Igualmente la Unión Interparlamentaria (Suiza) en Informations Constitutionelles et parlamenttaires. 
- Manuale ad uso dei Senatori del regno, Roma, Senato, 1886/1920.

- Manuale Parlamentare. Roma, Camera dei Deputati/Senato, 1924-1939; 1948-198. Comprende: Leg. ${ }^{a}$ XXVII, Ed. 1924; Leg. ${ }^{a}$ XXVIII, Ed. 1929; Leg. ${ }^{a}$ XXIX, Ed. 1934; Leg. ${ }^{a}$ XXX, Ed. 1939; Leg. ${ }^{a}$ I,Ed. 1948; Leg. ${ }^{a}$ II, Ed. 1955; Leg. $^{a}$ III, Ed. 1959; Leg. ${ }^{a}$ IV, Ed. 1964; Leg. $^{a}$ V, Ed. 1969; Leg. ${ }^{a}$ VI, Ed. 1973; Leg. ${ }^{a}$ VII, Ed. 1978; Leg. ${ }^{a}$ VIII, Ed. 1981.

Se han publicado múltiples ediciones de los reglamentos de ambas Cámaras en otras editoriales, como / regilamenti parlamentari, Milano, Giuffré, 1953 (que recoge también reglamentos de Francia, Alemania (R.F.), Gran Bretaña, Estados Unidos).

Vicenzo Longl y Mauro Stramacci, // Regolamento della Camera dei Deputati (1848-1968). Milano, Giuffré, 1968; publicadas por la Camera dei Deputati: Regolamento provisorio approvato il 28 novembre 1868 con la modificazioni posteriormente introdotte, Roma, 1883; Regolamento... 1888. Roma, 1888 (¿); Regolamento... 26 Gennaio 1891, Roma, 1891; Regolamento... 31 ottobre 1925/Roma, 1925; Regolamento... 31 ottobre 1925 con modificazione... 8 diciembre 1927. Roma, 1927; Regolamento... con la modificazioni... 1. ${ }^{\circ}$ maggio 1929, Roma, 1929; Regolamento... con le modificiazioni... 1. ${ }^{\circ}$ maggio 1929; del 19 dicembre 1929 e del 12 dicembre 1930/Roma, 1931; Regolamento... 14 dicembre 1938, Roma, tipografía della Camera dei Fasci e delle Corporazioni, 1939; Regolamento interno della consulta Nazionale... 11 gennaio 1946... Roma, (s.i.) 1946; Regolamento... 1959/Roma, 1959; Constituzioni della Republica-Regolamento della Camera dei Deputati... 1961... 1962. Roma, Carlo Colombo, 1966; Costituzione della Republica e Regolamento della Camera. Indice Analítico. Roma, 1971; 1973; Regolamento della Camera, con indice analítico... Roma, 1981.

El Senato igualmente ha publicado en ediciones independientes su Reglamento (1948; 1968; 1971, etc.). Entre los numerosos comentarios a los reglamentos G. BocCACCINI, Sistema político e regolamenti parlamentari. Milano, Giuffré, 1980. C. CicCONETTI, Regolamenti parlamentari... Padova, Cedam, 1979. T. MARTINES, "Regolamenti parlamentari e attuazione della Costituzione", en Studi parlamentari e di politica costituzionale, 3/1971; o La natura giuridica dei regolamenti parlamentari. Pavia, 1952. S. Tosı, «Innovazioni e conferme nelle recente riforma del regolamenti», en: Indirizzo politico del nuovo regolamenti della Camera dei Deputati. Milano, Giuffré 1973, pág. 5 y ss.

S. ROMANO, "Sulla natura dei regolamento delle Camera parlamentari», en Archivio Giuridico, 1906.

A. TESAURO, Sulla natura giuridica dei regolamenti parlamentari. TRAVERSA, «La natura giuridica delle norme dei regolamenti parlamentari», en // Regolamenti della Camera dei Deputati, Roma 1968.

Los reglamentos los recogen también los tratados de Derecho parlamentario, como en $V$. DI Cıolo, Le fonti del diritto parlamentare. Milano, 1975; (incluyendo comentarios a los principales artículos, notas bibliográficas por materias, etcétera).

Para los reglamentos de los grupos parlamentarios, la Secretaría General de la Cámara ha publicado una colección, I/ diritto dei partiti en Italia (1945-1970). Roma, 1971.

También esta misma Secretaría ha publicado disposiciones interpretativas 
del reglamento, como es: Circolari e disposizioni interpretative del regolamento emanante del Presidente della Camera (1948-1968), Roma, 1968.

\section{OTROS ESTUDIOS:}

M. MANCINI y V. GALEOTTI, Norme ed usi del parlamento italiano-trattato pratico di dioritto e procedura parlamentare, Roma, 1887. (Apéndice en 1891). V. GaleotTI, Regolamento della Camera dei Deputati, Roma, 1902.

Con carácter más general no hay que olvidar, /l Regolamento della Camera dei Deputati (Storia, Istituti, Procedure), Roma, 1968.

G. AMATO, Tendenze istituzionali e nuovi regolamenti parlamentari, en Indirizzo politico del nuovo regolamento della Camera dei Deputati, Giuffré, Milano, 1973.

R. AstRALDI, Le norme regolamentari del Parlamento italiano. Storia, esposizioni sistematica e confronti con regolamenti Stranieri Roma, Camera dei Deputati, 1932.

\section{OtRos MATERIALES}

Desde 1968 se cuenta con dos publicaciones, parte del trabajo conjunto de los servicios de documentación de las dos Cámaras del Parlamento italiano.

1. Repertorio legislativo e parlamentare (publicado por la Camera dei Deputati).

Es un índice general de la legislatura. Está subdividido en dos volúmenes: El primer volumen es diccionario por materias en el que están recogidas cronológicamente: la síntesis de las preguntas, interpelaciones, mociones, resoluciones y órdenes del día; la fecha, la sesión y un breve resumen de las principales cuestiones reglamentarias y constitucionales que han tenido lugar en la Camera dei Deputati o Senato; los títulos y contenido de los decretos presidenciales o ministeriales y circulares de interés publicadas en la Gazzetta Ufficiale; el título de las leyes y decretos de las regiones, etc. Es puesto al día anualmente. El segundo volumen está dedicado a las actividades parlamentarias de encuesta, reglamentos, etc.; a la actividad normativa del Gobierno y de las regiones; a la actividad de la Corte Constitucional y a la composición de la Cámara.

2. Resoconto dei lavori del Senato parlamentari (publicado por el Senato).

El «resoconto» está dedicado a la actividad legislativa del Parlamento: índice numérico y por materias de los proyectos de ley presentados en el Senato y Camera dei Deputati; índice de las leyes aprobadas en la legislatura, con indicación relativa a los "Atti parlamentari»; índice de los decretos-ley presentados con datos relativos a la conversión en ley, etc., así como reuniones del Parlamento en sesión conjunta.

Al igual que el repertorio se pone al dia anualmente.

\section{OTRAS PUBLICACIONES:}

- Manuale parlamentare. Editado al comienzo de cada legislatura alternativamente por la Camera dei Deputati y Senato della Repubblica; con- 
tiene además de las listas alfabéticas de diputados y senadores, leyes, reglamentos y otras normas de consulta en la actividad parlamentaria.

- Annuario Parlamentare. Esta publicación recoge la composición, funciones y estructura de los órganos constitucionales y de la Administración pública, así como Asociaciones y Organizaciones internacionales.

(Se publica desde 1948-1949. De 1928-1938 se denominó Agenda).

- Elenco dei Deputati. Lista de diputados, puesta al dia periódicamente, en el curso de la legislatura. Contiene además, la composición de la "Giunte" de las "Commissioni permanenti e speciali», de los "Gruppi parlamentari» y listas electorales de cada colegio.

- Deputati e senatori dell'ottavo parlamento Republicano (editado por la Navicella). Comprende la biografía de diputados y senadores; resultados de las elecciones; composición de la Camera y del Senato; datos sobre el Presidente de la República y del Gobierno; biografías de los ministros no parlamentarios.

Colecciones de discursos publicados por la Camera dei Deputati: Discorsi parlamentari del Conte Camillo di Cavour; de Urbano Rattazzi; de Quintino Sella; de Marco Minghetti; de Agostino Depretis; Pasquale Stanislao Mancini; Giuseppe Zanardelli; etc.

A lo largo de la historia parlamentaria italiana, la Camera dei Deputati ha venido publicando una serie de publicaciones periódicas que daban noticia sobre la actividad de la Cámara:

- Bollettino parlamentare. 1927-1938.

- Suplemento bibliográfico del Bolletino parlamentare. (1930-1938) recogía las últimas adquisiciones de las Bibliotecas de ambas Cámaras.

- Suplemento legislativo del Bollettino parlamentare. (1933-1938), contiene relación de «disegni" e "proposte di legge» presentadas al Parlamento durante las legislaturas en curso y "leggi" y "decreti-leggi" aprobadas en el mismo período.

- Bollettino delle Assemblee legislative. (1939-1940), en sustitución del Bollettino parlamentare publicado por la Camera dei Fasci.

- Bollettino di informazioni costituzionali e parlamentari. (1950 y ss., con la interrupción de algunos años). Ha publicado un indice Generale del Bolletino di informazioni costituzionali e parlamentari (1950-1972). Recoge las constituciones y leyes electorales de Italia y otros países. Reglamentos, documentación de organizaciones internacionales, Unión Interparlamentaria, etc.

- Bolletino di legislazione comparata. 1966 y ss., recoge legislación extranjera y otra documentación agrupada por materias.

La revista Quaderni Costituzionali, dispone de una sección fija, "Le istituzioni in Italia», dentro de la cual dedica una parte a Parlamento donde se reseñan y estudian diversas cuestiones.

Finalmente indicamos la publicación de estudios en revistas especializadas de Derecho Constitucional y parlamentario: 
- Rivista Trimestrale dei diritto pubblico.

- Rassegna Parlamentare.

- Parlamento, etc.

\section{FRANCIA}

\section{Publicaciones Parlamentarias}

La documentación parlamentaria francesa al igual que en el resto de los Parlamentos, recoge las publicaciones oficiales de sus debates, y los trabajos y las decisiones del Parlamento; es decir, lo que el Parlamento hace y lo que en el Parlamento se dice*. A partir de 1789 las actas contenían resúmenes de los debates. Desde 1800 a 1805 se recogía en el Journal del Débats et lois du pouvoir legislatif, et des Actes du Governement. Desde 1806, en el Journal de L'Empire.

En 1814 el procés-verbal se transforma en un Compte-rendu mucho más completo, y los discursos comienzan a ser registrados "in extenso".

En 1852 se decidió publicar dos documentos separados: un pequeño sumario y un "Compte-rendu" analítico en el que los debates, sin ser publicados palabra a palabra, fueron presentados bajo la forma de un resumen extenso.

Desde la Revolución, se publicaba en Le Moniteur el "Compte-rendu» «in extenso" de los debates. Estos "Comptes-rendus" no eran oficiales e incluso en los primeros años se cometian inexactitudes en la reproducción de los textos adoptados por la Asamblea.

En la Restauración, Le Moniteur obtuvo un contrato para redactar y publicar los "Comptes-rendu".

En 1848, bajo la Asamblea Constituyente, la tarea fue de la Cámara y el Compte-rendu "in extenso" llegó a ser verdaderamente un documento oficial. Desde entonces, éste y los otros documentos parlamentarios son publicados en el Journal Official. (Este constituye la Gaceta Oficial del Gobierno. Su historia se remonta a la Revolución, 24 de noviembre de 1789; el editor Charles Joseph Panckocke publicó el primer número de un periódico conocido bajo el nombre de La Gazette Nationale o Le Moniteur Universel, generalmente llamado: Le Moniteur. En 1868 el Gobierno vendió el derecho de publicar una Gaceta Oficial a la firma Wittersheim: la nueva publicación tomó el nombre de Journal Officiel).

(Las publicaciones parlamentarias francesas fueron reeditadas, en forma de Colección, con todas las correcciones necesarias en: Annales des débats parlementaires, publicado desde 1863 a 1950).

* Las actas sobre las reuniones de los Estados Generales desde el siglo xv hasta 1789 pueden consultarse en el Archive National, Archives Nationales. Caja K 674 a K 679 . O en la Bibliothéque Nationale, Manuscrits. MS. FR. 7517-23; 10867-83; 16248-58; 16262-66. 
Cada Cámara conserva como instrumento de referencia su propia colección de documentos parlamentarios: Archives Parlementaires, publicados desde 1787 a 1860 , editada por M. J. Maridal y M. E. Laurent. Los documentos que aquí se conservan comprenden: copias de "comptes-rendu" «in extenso", todos los proyectos de ley y proposiciones, informes de Comisiones, "procés-verbaux" de comisiones designadas en las circunscripciones electorales y diversos índices de autores y materias.

Desde 1893, la Chambre des Deputés publica Resumé Genéral des travaux legislatif.

\section{LAS PUBLICACIONES EN LA ACTUALIDAD}

Comprenden: Debates de las sesiones plenarias (los debates de las Comisiones no se publican, conservándose a disposición de los miembros de las Comisiones correspondientes. No obstante, existen algunas Comisiones, como las de encuesta, que sí publican los debates).

\section{Sénat}

1. Journal Officiel. Documents.

2. Journal Officiel. Debats

a) Compte-rendu.

b) Questions.

\section{Assemblée Nationale.}

1. Journal Officiel. Documents.

2. Journal Officiel. Debats.

a) Compte-rendu.

b) Questions.

- Documents: Comprende la documentación parlamentaria, ya sea de origen gubernamental (mensajes del Presidente de la República, declaraciones de los ministros, proyectos de ley) o de origen parlamentario (alocuciones pronunciadas por el Presidente de la Asamblea, proposiciones de ley o de resolución, informes de las Comisiones Permanentes, especiales "ad hoc", de encuesta o de control, informes de las Comisiones mixtas paritarias de la Asamblea Nacional-Senado).

Cada documento se numera en su cabecera por año parlamentario para el Senat y para la Asamblea Nationale numerados por legislaturas. Se anuncian desde su aparición en la edición del Journal Officiel, Lois et Décrets. Se señala en ellos la sesión plenaria en que se presentó. La paginación es independiente para cada número de la serie. Al pie de la primera página hace referencia a otros documentos presentados en ambas Cámaras en relación con el tema.

Pueden ser obtenidos en el Bureau de venta de los Journaux Officiels, 25, rue Dexaix, 75015 París, o bien en la libreria de la Documentation française, 29, Quai Voltaire, 75340 Paris Codex 07. 
Los documents de l'Assemblée Nationale están divididos en dos series:

a) Ordinaria (proyectos, proposiciones de Ley, etc.).

b) Serie presupuestaria (proyectos de leyes de finanzas: el Presupuesto de un ejercicio da lugar a varias series de publicaciones: "projet de loi de finances"; "budget» votado;el/los "projets de loi de finances» rectificados; "projets de loi de réglement" definitivo; "Compte Général de l'Administration des finances").

Los «projets de loi» de carácter presupuestario se les llama «azules» por el color tradicional de su cubierta. Aparecen con un número en la serie de documentos parlamentarios. Los anexos no están numerados, (a excepción del «Rapport economique et financier»); tienen cubiertas azules, amarillas o blanca.

- Loi de Finances: I. El "projet de loi de finances" y sus anexos se publican en fascículos por la Imprimerie Nationale; (por ejemplo, en 1973 se publicaron 90 fascículos presupuestarios: "Projet de loi de finances pour 1973"; "Rapport économique et financier", etc. II. "La loi de Finances" y los "decrets de repartition» se publican en el Journal Officiel, edición de «lois et décrets»; también se editan en tirada aparte en "textes d'intérêt géneral».

- Le Budget. El presupuesto votado se publica en fascículos separados (en cubierta verde) para cada ministerio. En estos fascículos se da el análisis de los créditos que se han votado y la estructura y atribuciones de cada Ministerio.

Otra serie de fascículos de cubierta blanca, titulados «Budget de... Nomenclature d'exécution" proporciona la lista de rubricas presupuestarias.

- Lois de finances rectificatives (dichas colectivas).

Los "projet de loi» de finanzas rectificativa se publican en la serie de Documentos parlamentaria bajo cubierta azul.

La ley votada y los decretos de reparto se publican en el Journal Officiel.

Cuando algún proyecto de ley de finanzas no se ha depositado en la 2. ${ }^{2}$ Sesión del Parlamento, el Ministerio de Economia y Finanzas publica un Rapport sur l'evolution de l'economie nationale et des finances publiques.

- Loi de Règlement. Se publica en los Documentos parlamentarios el "Projet de loi portant règlement dèfinitif du Budget de..." y se acompaña de un «Rapport de la Cour des Comptes sur le projet de loi portant règlement dèfinitif du budget de..." y de la "Declaration gènérale de conformité sur la gestion..."; "La loi de Règlement» se publica en el Journal Officiel.

La Assemblée Nationale publica indice de materias y autores para cada legislatura.

El Sénat publica indice de autores y materias por años parlamentarios. En los documentos del Sénat se hace referencia al número y legislatura de la Assemblée nationale. 
- Dèbats.

Los debates de la Assemblée Nationale y del Sénat se publican en el Journal Officiel, edición: «Dèbats Parlementaires».

Existe una edición publicada en volúmenes: Dèbats de l'Assemblée Nationale y Annals des dèbats du Sénat.

Los debates se publican en una edición íntegra y otra resumida:

a) El Compte-rendu stenographique, «in extenso», es el documento más completo de los trabajos de las Cámaras. Se publica generalmente un ejemplar para cada día de la sesión. El "compte-rendu" de cada sesión se precede de un sumario indicando los asuntos discutidos, las decisiones adoptadas y los nombres de los que han tomado la palabra. A continuación comienza el "compte-rendu» de la discusión con el examen del proceso verbal de la sesión precedente; se sigue con las diferentes materias tratadas hasta el anuncio de los informes presentados en la Cámara, con su número de publicación del orden del día de la siguiente sesión. A menudo se incluyen largas listas de proyectos y proposiciones de ley, informes, interpelaciones y otros documentos análogos. De estas comunicaciones se hace un registro y no son leídos en la Asamblea. Al final del número figuran anuncios diversos, tales como el orden del día, datos sobre la "Conference des Presidents", las reuniones de comisión para el día siguiente, etc. y un anexo con los nombres de los Diputados designados como informadores. De vez en cuando, se inserta una sección especial de preguntas escritas y las respuestas a éstas.

Los debates se transcriben con gran exactitud, no sólo en discursos propiamente dichos, sino también las interrupciones, observaciones, con el nombre del autor de los mismos.

b) Compte-rendu analytique. Tiene por objeto fijar la esencia de los debates: se suprimen las declaraciones formales del Presidente, así como todos los anuncios suplementarios (excepto los concernientes al orden del día de la siguiente sesión; se hace un resumen de los discursos, en el cual todas las frases no indispensables se eliminan, reduciendo su longitud a dos tercios del «compte-rendu» integral.

Se prepara con una gran rapidez por personal especializado. Se fotocopia cada hoja, divulgándose inmediatamente, generalmente al dia siguiente de la celebración de los debates.

Este “compte-rendu analytique» va precedido de un “compte-rendu sommaire" resumen muy condensado que aparece horas después de finalizada la sesión:

c) Senata: Indices de los Debats. El Senado publica indices anuales de autores (iniciativas, intervenciones, enmiendas): bajo materias, remite al número del proyecto de ley y fecha; o fecha y página; e índice de materias. (Ver "Otras publicaciones").

d) Senata: Indices de «Questions et des Responses des Ministres». Estos indices se publican y difunden por el Journal Officiel vendido juntamente con la serie "Débats parlementaires". (Ver "Otras publicaciones"). 
e) Assemblée Nationale: Indices. Publica por una parte: Tables Gènerales des documents et dèbats parlementaires (Indice de materias y de autores para cada legislatura); y por otra: Tables annuelles des dèbats de l'Assemblée Nationale (Indice de materias, de autores y de «questions").

\section{OTRAS PUBLICACIONES}

Ambas Cámaras publican otros trabajos de gran utilidad para el seguimiento de los trabajos parlamentarios.

\section{La Assemblée Nationale:}

1. Bulletin de l'Assemblée Nationale. (Recoge el panorama general de las sesiones públicas. Los trabajos de la semana, clasificados por Ministerios; las novedades de la Asamblea; el calendario de los próximos trabajos; los documentos parlamentarios puestos en distribución).

De periodicidad semanal aparece cada martes durante las sesiones y una o varias veces en los periodos de no sesiones. Su difusión es gratuita. El Bulletin se distribuya a todas las instituciones y personas que lo soliciten (servicios de informaciones parlamentarias, publicaciones estadísticas, etc.). Se publican anexos a este Bulletin, como es «Bilan de la $5{ }^{\ominus}$ legislature: 2 avril 1973-2 avril, 1978."

2. Bulletin des Commissions. (Recoge los trabajos de las diversas Comisiones y decisiones tomadas. Aparece los miércoles durante las sesiones.)

3. Recueil des engagements èlectoraux. (Llamado “Barodet"). Se publica después de cada elección general en 2 volúmenes.

4. Feuilleton: El orden del día de la Assemblée, de las Comisiones, indicación de los documentos difundidos. Los días de la sesión aparece diariamente.

5. Textes adoptés par l'Assamblée. (Llamados también "petites lois")

6. Recueil des lois. (Contiene los textos de las leyes adoptadas por el Parlamento y promulgadas, así como el índice de respuestas a las preguntas orales. Se publica al final de cada sesión.

7. Recueil mèthodique des travaux prèparatoires. (Contiene los documentos, índices, debates relativos a determinadas leyes. La periodicidad de esta publicación es irregular y se vende en la Dirección del Journal Officiel).

8. Notices et portrait des deputés, par dèpartement (Publicado para cada legislatura, con puestas al día, con ilustraciones de fotografias). Es una fuente de referencia para el estudio sociodemográfico de los parlamentarios. Indicaciones más detalladas se encuentran en la Encyclopèdia pèriodique économique, politique et administrative, Paris, Société Génerale de Presse, 1954 y ss. 
9. Liste alphabetique, et par circonscription electorale, de Mmes. et MM. les députés. (Esta lista indica la dirección, grupo y Comisiones; comprende también la organización y las atribuciones de los servicios. Se publica anualmente al principio de la sesión de primavera).

10. Reseignements sur les servicies de l'Assemblée Nationale. (Se publica al comienzo de cada legislatura.)

11. Statistiques desde 1900 y ss. sobre los trabajos parlamentarios, de publicidad anual.

12. Historique des scrutins, de publicidad anual.

13. Textes relatifs aux pouvoirs publics. (Contiene la Constitución, leyes orgánicas, textos legislativos y reglamentarios, en edición de hojas intercambiables de puesta al día. Su difusión es interna.

14. Tables generales de documents et débats parlementaires, établies par le service des Archives. Paris, Imprimerie de l'Assemblée Nationale: 1. Table des matieres; 2 . Table nominative. Por año y legislatura.

15. Tables de questions et des reponses des ministres. Paris, Imprimerie de J. O. Comprende repertorio analítico y alfabético anual.

16. Les Gouvernments et les assemblées parlementaires sous la Cinquième Rèpublique, 1, de 1959 a 1974. París, 1975.

El Senat publica:

1. Bulletin d'informations rapides (Este boletín describe las sesiones públicas y la vida de las Comisiones y reseña los documentos aparecidos. Su periodicidad es semanal, durante las sesiones, destinado especialmente a las autoridades locales. Es gratuito y lo difunde el Servicio de Información del Senado. Publica números especiales anualmente: "L'activité du Sénat au cours de l'année $19 \ldots$...

2. Bulletin des Commissions. (Da a conocer el "compte-rendu" de los trabajos de Comisiones. Es semanal durante las sesiones; de difusión interna).

3. Feuilleton. (Recoge el Orden del Día de las sesiones, reuniones de las comisiones, documentos puestos en distribución; etc.).

4. Textes adoptés par le Sénat au stade transitoire ou définitif. (Esta publicación es el equivalente a las "petites lois" de l'Assemblée Nationale).

5. Groupes et Commissions. (Menciona igualmente los miembros nombrados por el Senado para el Consejo Constitucional y los Delegados del Senado a la Haute Court de Justice y en las diversas Asambleas Europeas).

6. Relevé individual des principaux votes. (Scrutine publics).

7. Notices et portraits (Biografias con ilustraciones de fotografias. De publicación anual).

8. Liste alphabétique, et par circonscription électorale, de Mmes. et M.M., les sénateurs. (Comprende direcciones, composicion de los 
grupos y Comisiones; incluye también indicaciones sobre los servicios del Senado).

9. Tables des débats établies par le service des Archives du Sénat. Paris, Imprimerie del J.O. "Table des matieres et Table nominatif». Publicación anual.

10. Table dés questions écrites et orales de l'année. París, Imprimerie des J.O. (Comprende repertorio analítico y alfabético).

\section{REgLAMENTOS}

Las Cámaras publican al comienzo de cada legislatura su respectivo Reglamento y sus sucesivas modificaciones.

Igualmente aparece publicado en el Diario Oficial, Journal Officiel. También en el Manuel á l'usage des membres du Sénat et de la Chambre des Representants.

Se localizan en publicaciones periódicas como, Informations Constitutionelles et parlementaires, publicada por la Unión Interparlamentaria; y en Boletín de Legislación Extranjera (España, Cortes).

Existen ediciones singulares* (Assemblee Nationale. 1873. Versailles, Cerf et Fils, 1873; 1878. París, Motteroz, 1878; 1880; 1885. París, A. Quantin, 1885; 1893, París, Motteroz, 1893; 1947. Paris, 1947; 1959. Revue de Droit Public et Science politique, n. ${ }^{\circ} 75,1959 ;$ 1967. París. París, 1967; 1980. París, 1980. 1981. París, 1981; Senat, 1869. París, Dupont, 1869; 1879. Versailles, Imp. du Senat, 1879; 1891. París, P. Mouillot, 1891; 1903. París, P. Mouillot, 1903; 1959. París, 1959; 1960: París, 1960;1962. París, 1962; 1963.París, 1963. 1966. París, Imp. des Journaux Officiels 1967; 1968. París, Imp. Journaux Officiels, 1968; 1978. París, 1978.).

De las ediciones colectivas señalamos: $R$. Bonnard, Les réglements des Assemblées législatives de la France depuis 1789. Paris, Sirey, 1926.

Los reglamentos de las Asambleas han sido objeto de varios estudios:

Rottner, A. Les réglement provisorie de l'Asemblée Nationale. Paris, 1959. (D.E.S. de science politique. Droit. París, 1959).

RuzIE, D., "Le nouveau réglement de l'Assemblée Nationale", en Revue du Droit Public et de la Science politique, 1959, sept.-oct., 864-914.

* El Senado italiano publicó, en 1969, Regolamenti parlamentari dei Paesi della Comunitá Europea, Roma, 1969, donde recoge los reglamentos de: Bélgica, Francia, Italia, Luxemburgo, Países Bajos, Alemania, Parlamento Europeo. En el caso de Francia recoge el de la Asamblea Nacional de 3 de junio de 1959, con las modificaciones de 18 de diciembre de 1959; 5 de diciembre de 1960; 4 de marzo de 1961; 19 de diciembre de 1963; 3 de julio de 1964; 6 de octubre de 1964; 26 de abril de 1967. Y del Senado, de 16 de junio de 1959, con modificaciones de 9 de junio de 1959; 27 de octubre de 1960; 20 de julio de 1962; 16 de mayo de 1963; 16 de junio de 1966; 14 de mayo de 1968. 
BerliA, G. “La Constitución et les débats sur les Réglements des Assemblées parlementaires", en Revue du Droit Public et de la Science politique, 1959,mayo-junio, 566-570.

HAMON, L. Le controle par le Conseil Constitutionnel des Réglements provisoires de l'Asemblée Nationale et du Sénat. Recueil Dalloz, 1959, 11 noviembre, Jurisprudencia, 501-507.

\section{OtRos MATERIALES}

Para la investigación sobre el Parlamento francés no se cuenta con muchos ensayos bibliográficos, como puede verse en el capitulo de obras de referencia bibliográficas; no obstante, existen instituciones de estudios parlamentarios, guias de investigación parlamentaria, así como revistas especializadas que cubren esa laguna.

Respecto a las instituciones, existen dos Centros de investigación en el campo de estudios parlamentarios contemporáneos:

- Centre d'étude des parlements (CEP), que es uno de los equipos de investigación del Centre d'analyse comparative des systémes politiques du Département de Science Politique, de la Université de Paris I y asociado al Centre National de la Recherche Scientifique.

- Centre d'étude de la vie politique française contemporaine (CEVIPOF), de la Fondation Nationale des Sciences Politiques, y asociado, también, al Centre Nationald e la Recherche Scientifique.

Por otra parte, la Association Française de Science Politique ha creado el groupe de spécialistes des études parlamentaires francaises (GETUPAR), que se encarga de reunir todos los trabajos de investigación sobre el Parlamento francés, convocando Mesas Redondas sobre el trabajo parlamentario en 1954 o en 1970 sobre el papel de los parlamentos en las democracias modernas de tipo liberal.

Finalmente, un equipo de investigación privada, el Institut de mesure de l'activité parlementaire (IMAP), que da a conocer las actividades parlamentarias a los periodistas.

Las Guias de Investigación están dedicadas a la V. ${ }^{a}$ República:

EMERI, Claude, "Les institutions de la Cinquième République: état des travaux", en Revue francaise de Science Politique, 15 (2), 1965, 297-330.

AUBER, Véronique et PARODI, Jean-Luc, Analyse Bibliographique du Parlement de la Cinquième République, 31 (1) 1981, $227-264$.

(Recoge los trabajos parlamentarios en ocho apartados según una clasificación temática: 1. Obras generales; 2 . Elecciones y representación; 3. Los parlamentarios; 4. Fuerzas políticas; 5 . Organización y procedimiento; 6 . Relaciones con otras instituciones; 7 . Influencia y decisión política; 8 . El parlamento en el sistema político global. Los análisis bibliográficos principales se comentan a la ca- 
beza de cada epígrafe. Siguen los trabajos citados por orden cronológico de su aparición. Este método ofrece ventaja de permitir una mejor evaluación progresivà de las investigaciones.)

Las revistas especializadas juegan un papel importante en la difusión de los trabajos parlamentarios:

- Revue du Droit Public et de la Science Politique en France et á l'étranger. Hasta 1972 publicaba una "Chronique constitutionnelle et parlementaire française", que incluía en "Vie et Droit parlementaire" textos de referencia, que permitian evaluar la práctica de las instituciones francesas. A partir de 1972 contiene otra crónica regular: "Analyse des lois et décrets" y a partir de 1976, "Chroniques des questions parlementaires écrites".

- Revue Française de Science Politique, publica estudios relativos al proceso legislativo. (Bimestral).

- Revue politique et parlementaire (bimestral), con su sección regular "memento parlementaire" en que reseña las actividades más importantes de la Asamblea, textos definitivamente adoptados y publicados, proyectos y proposiciones puestas en distribución, etc., así como «tribuna du parlementaire" donde se incluyen las listas de los elegidos.

- Projet.

- Pouvoirs (trimestral), desde 1977, con su "Chronique constitutionnelle française», puesta al dia, trimestralmente, de la actividad parlamentaria y otros órganos constitucionales, incluyendo bibliografía complementaria y reciente en alguna de las materias reseñadas.

- L'Annuaire de législation française et étrangere (París CNRS) publica una crónica anual, ofrece un panorama general de la vida política francesa.

- La Gazette du Parlement, de publicación semanal, proporciona una síntesis documentada de la vida parlamentaria.

- Le Journal du Parlement, publicación de organismo privado, su contenido no es de demasiado interés.

Independientemente de las publicaciones oficiales, existen ediciones privadas que recogen otros materiales de interés; asi en el caso de la recopilación de biografias por Jean Jolly, dir., Dictionaire des parlementaires françaises. Notices biographiques sur les Ministres, Deputés et Sénateurs françaises de 1889 a 1940. Paris, Presses Universitaires de France 1960 y ss. 8 v. Está precedido de la lista de los Ministerios de Francia de 1871 a 1940; de los Ministros de 1871 a 1940; de los Presidentes del Senado de 1876 a 1940; de los Senadores de 1876 a 1940; de los miembros de la Asamblea Nacional de 1871 a 1876; de los Presidentes de la Asamble Nacional y de la Cámara de los Diputados de 1871 a 1940 y de los Diputados de 1876 a 1940 . Contiene la biografía de senadores y diputados, ordenados alfabéticamente: reseña su filiación política, años en que presenta a las elecciones y actividades parlamentarias y políticas.

Para el conocimiento de los estudios sociológicos de los parlamentarios es buena guía bibliográfica el trabajo de PIERRE BIRNBAUM, «Modernisation du Système politique ou transformation de la classe dirigente", en Pouvoirs, 4/1978, 51-59. 
YVES DAUDET, La Presidence des Assemblées parlementaires françaises... Paris, Presses Universitaires de France, 1956. Recoge desde 1873-1962 nombres de los Presidentes, duración, causa de sus ceses, etc.

\section{OTROS TRABAJOS SOBRE LOS PARLAMENTARIOS FRANCESES:}

CAYrol, Roland; PARODI, Jean-Luc; YSMAL, Colette: Le deputé français. Paris, Presses de la Fondation Nationale des Sciences Politiques, 1973.

Cayrol, Roland; PAROdI, Jean-Luc; YSMAL, Colette: "Les députés français et le systéme politique». Revue francaise de Science Politique, (1) 1975, 72-105.

Birbaum, Pierre: Les sommets de l'Etat, essai sur l'élite du pouvoir en France. Paris, Le Feuil, 1977.

CHARLOT, Jean: «Les élites politiques en France de la troisième á la cinquième république", en Archives européennes de sociologie, (1) 1973, 78-92.

BECARUD, J.: «Noblesse et représentation parlementaire: les députés nobles de 1871 á 1968", en Revue française de Science Politique, (5) 1973, 972-993.

Al igual que en otros Pariamentos, Francia ha publicado colecciones de discursos como:

Ernest PICARD, Discours Parlementaires. Paris, E. Plon, 1882-1886.

THIERS, Discours Parlementaires, 16 v. Paris, Calmann Levy, 1879.

Jules FAVRE, Discours Parlementaires. Paris, 1881.

BerRYER, Discours Parlementaires, Paris, Soye, 1880-1883. 5 v.

\section{HISTORIA}

Las fuentes históricas sobre el Parlamento francés son abundantes a lo largo de los siglos XIX y XX.

\section{OBRAS GENERALES:}

BASTARD-D'EstAng: Vicomte de: Les Parlements de France. Essai historique sur leurs usages, organisation et autorité. Paris, Didier, 1857.

CORCIULO, María Sofia: La nascitá del régime parlementaire in Francia, Varese, Giuffré, 1977.

COUYBA, Ch.: Les grands institutions de France. Les parlements françaises. Paris, 1914.

Gulzot, Francois: Histoire parlementaire de France. Paris, Michel Levy Frers, 1863.

POR PERIODOS:

GLASSON, E.: Le parlement de Paris depuis Charles VII à la Révolution. Paris, Hachette, 1901. 
SAULNIER, Frederic: Le Parlement de Bretagne, $1554-1790$ (S. I.) y Rones, (S. a.).

DESMAZE, Charles: Le Parlement de Paris... avec une notice sur les autres Parlements de France et le tableau des premiers presidents generaux de la Cour de Paris. (1334-1859). Paris, Michel Levy Frèrs., 1859.

MAJOR: "Representative Institutions in Renaissance France, 1422-1559". En S/C, 1960.

SOULE: «Les Etats Géneraux de France (1302-1789). Etude historique comparative et doctrinale». En SIC, 1968.

BUCHEZ y Roux: Histoire parlementaire de la Révolution française ou journal des Assemblées Nationales depuis 1789 jusqu'en 1815. Paris, 1834-1838.

PierRe, Eugene: Histoire des Assemblées politiques en France 1789 á 1876. Versailles, Cerf et fils, 1877.

Corciulo, María Sofia: Le instituzioni parlamentari in Francia. Cento giorni e seconda restaurazione (1815-1816). Napoli, Guida Editore, 1979.

BASTID: Les institutions politiques de la monarchie parlementaire française (18141848). Paris, 1954.

BERGASSE, Henry: Histoire de l'Assemblée, des élections de 1789 aux élections de 1967. Paris, 1967.

PRIOURET, Roger: La République des députés. Paris, Grasset, 1959.

\section{BIBLIOGRAFÍA}

No existe ninguna obra de conjunto sobre el Parlamento francés que recoja, a la vez, aspectos de organización interna, personal, papel dentro del sistema político, etc. No obstante, para el conocimiento del Parlamento de la III y IV República existen algunos trabajos básicos, como:

PIERRE, Eugène, Traité de Droit politique, electoral et parlementaire. Paris, Librairies-Impremieries réunies, 1893. Contiene un amplio índice analítico de gran utilidad porque recoge en él todos los conceptos de Derecho parlamentario remitiendo al número del epígrafe correspondiente.

Poudra, Jules, Traité pratique de Droit parlementaire. Versailles, 1878. Trata de explicar, manejando el Bulletin des lois, Le Moniteur, Archives y Anales parlementaires, el funcionamiento de las Cámaras (del Poder legislativo: el derecho de ejercerlo, derecho de las Cámaras en materia de finanzas, etc., de la elaboración de las leyes, control parlamentario, etc.). Estudio de los parlamentarios, inmunidades e incompatibilidades, etc.

Lidderdale, D. W. S., Le Parlement français. Paris, Foundation Nationale des Sciences Politiques, 1964. No sólo estudia la organización y procedimiento del Parlamento en la $3 .^{a}$ y $4 .^{a}$ República, sino los orígenes históricos: Estados Generales, antes de 1789 y las Asambleas legislativas de 1789 hasta la caída del Segundo Imperio. (Existe otra edición en inglés: Parliament of France. London, 1951). 
No hay que olvidar los estudios de F. Goguel, Le travail parlementaire en France. París, 1968; de E. BLAMMT, Techniques parlementaires. París, 1969 (?) y Phillppe Pondaven, Le Parlement et la politique exterieur sous la IV Republique. Paris, Press Universitaires de France, 1973.

Sobre el Parlamento de la $V$ República se encuentran, por un lado, estudios dentro de los tratados de Derecho Constitucional como, M. DUVERGER, "Le Parlement", en: Institutions politiques et Droit Constitutionel. Paris, Presses Universitaires de France, 1973; y por otro, algunos ensayos con sucesivas puestas al día:

WILLIAMS, Philip M.: The French parliament (1958-1968). London, G. Allen and Unwin, 1968.

Avril, Pierre: Le régime politique de la Cinquiènme République. Paris, Librairie Générale de Droit et de Jurisprudence $1964 ; 2 .^{a}$ ed. puesta al día, 1967; 3. ${ }^{\text {a }}$ ed., puesta al dia, 1975; $4 .^{a}$ ed., puesta al día 1979.

-: Pierre: Les français et leur Parlement. Paris, Casterman, 1972.

GICQuel, Jean: Essai sur la pratique de la Cinquième République. Paris, Librairie Générale de droit et de Jurisprudence, 1968; puesta al día: Reflexions sur la deuxième décennie du régíme, 1977.

GuiChARD-Ayoub, Eliane: Etudes sur le Parlement de la $V^{\theta}$ République, par Eliane Guichard-Ayoub, Charles Roig et Jean Grangé. Paris, Presses Universitaires de France, 1965. Además de estudiar la evolución del Parlamento en 1959, el carácter representativo del Senado a través de las elecciones del 26 de abril de 1959 analiza su organización: aspectos técnicos y políticos del orden del día. En anexos, cuadros estadisticos de proposiciones de ley examinados definitivamente desde 1959 a 1962, indicando fecha, grupo parlamentario y materia; proposiciones en curso; proposiciones de ley no discutidas; preguntas orales con indicación de fecha y materia; grupos politicos de las Asambleas; número de sesiones, etc.

Cotteret, J. M.: Le pouvoir législatif en France. Paris, Librairie Générale de Droit et de Jurisprudencia, 1962. Estudio del origen del poder legislativo y de su decadencia. Acompaña bibliográfia. dos ensayos:

Sobre el nuevo papel del Parlamento bajo la $V$ República pueden verse

Chandernagor, André: Un Parlement, pourquoi faire? Paris, Gallimard, 1967; analiza la crisis mundial del Parlamento y las vías de renovación: métodos y medios de trabajo.

Birngaum, Pierre: Reinventer le Parlement par P. Birnbaum, Francis Hamon et Michel Troper. Paris, Flammarion, 1977.

Algunos estudios de Derecho parlamentario de la $V$ República presentan importantes síntesis de trabajos anteriores: 
BOURDON, Jean: “Les Assemblées parlementaires sous la Cinquième République", en Notes et études documentaires, núm. 4463-4464, 17 de abril de 1978.

MASCLET, Jean-Claude: Le róle du député et ses attachés institutionnelles sous la Cinquième République. Paris, Librairie Générale de Droit et de Jurisprudence, 1979.

\section{OTROS ESTUDIOS}

INCOMPATIBILIDADES:

ANCEL, Frederic, Les incompatibiliés parlementaires sous la $V^{e}$. République. Paris, Presses Universitaires de France, 1975.

Cedara, M. Les incompatibilités parlementaires en France et à l'étranger. Paris, La Documentation Française, 1974.

INVIOLABILIDAD:

SOBULIER, Gerard, L'inviolabilité parlementaire en Droit francais. Paris, Librairie Générale de Droit et de Jurisprudence, 1966.

SenAdo:

Desplaces, Henri, Sénats et Chambres Hautes. Paris, Hachette, 1893. (Análisis histórico y su significado).

Gomel, Charles, Essai historique sur les Chambres Hautes françaises et étrangéres. Paris, 1873.

GUICHARD, E., Du caractére représentatif du Sénat à travers les élections du 26 avril 1959. Paris, 1962.

MIDY, C. Henri, Le Sénat, son role constitutionnel, sa composition. Paris, Paul Dupont, 1875.

SMETS, Georges, La reforme du Sénat. Bruxelles, etc. J. le Bave, 1919.

Estudios de Carácter General Sobre el Senado:

MARICHY, Jean-Pierre, La deuxième Chambre dans la vie polítique française depuis 1875 (Thése, Droit), Toulouse, 1967.

MASTIAS, Jean, Le Sénat de la Cinquiéme République: reforme et renouveau. Paris, Economica, 1980.

MOUTET, M., "Le Sénat dans la V. République». En Revue socialiste, 1959, 149-171.

PERnot, G. "Le Sénat de la V ${ }^{\ominus}$. République». En Revue politique des idées et des institutions, 1959, 129-136.

ROCHE, J., "Le Sénat de la République dans la Constitution de 1958. En, Revue du Droit Public et de la Science politique, 1959, 1126-1234. 
COMPETENCIA LEgISLATIVA:

CHELI, E., «L'ampliamento dei poteri normativi dell'ejecutivo nel principali ordinamenti occidentali, en Rivista trimestrale di Diritto Pubblico, 1959, 463-528.

DuRAND, P., "La decandence de la loi dans la Constitution de la Ve. République». En La Semaine juridique, 1959, Doctrine, 1470.

Gaudemeny, P. M., "La loi dans la Constitution de 1958", Public Law, 1981, 386-397.

Groux, J., “Les domaines respectifs de la loi et du réglement d'après la Constitution de 1958. Essai d'établissement d'un bilan de la pratique suivié depuis l'entrée en vigueur de la Constitution». En Notes et ètudes documentaires, núm. 2.908, 1962; 2.959, 1963.

MontANÉ DE LA RoQue, P. “L'article 38 de la Constitution du 4 octobre 1958 et la loi de pouvoirs spéciaux du 4 février 1960". En Mélanges offerts á Jacques Maury, Paris, Dalloz Sirey, 1960, pp. 199-222.

Parlamentarismo Mayoritario:

PARODI, Jean-Luc, «Forces politiques, institutions et système majoritaire», en Projet, 1967, marzo, 269-283.

PARODI, Jean-Luc, "Les difficultés du parlementarisme majoritaire", en Revue française de Science Politique, (5) 1967, 928-931.

PARODI, Jean-LuC, "La Cinquiènme République et le système majoritaire" (Thése, 1973).

Grupos Parlamentarios:

FERraRI, Pierre; MaISL, Herbert, Les Groupes communistes aux Assemblées parlementaires italiennes (1958-1963) et français (1962-1967). Paris, Presses Universitaires de France, 1970.

Y en Numerosas Memorias y Tesis:

Simonny, Marc, Les Groupes parlementaires de la majorité á l'Assemblée Nationale, 1968-1978. Thése. Paris II, 1978.

DISSEZ, Henri, L'étude d'un Groupe Parlementaire: le Cas du Groupe MRP au Sénat sous la Quatrième et la Cinquième République. Memoire, DES.

Sobre el Grupo Socialista.

Se encontrarán informaciones en la Nouvelle revue socialiste.

Sobre el Partido Comunista:

— "L'élu d'aujord'hui", en Bulletin de l'élu comunista, 1975-1977. 
- Communisme et départements d'aujourd'hui, 1978, enero, 12 p.

Estudios que contribuyen a establecer balances del Parlamento francés:

Avril, P. "The French Parliament», en: European Parliament, symposium on European integration and the future of Parliament in Europe. Luxembourg, 1975.

COUDERC, Michet, THIERRY, Hubert, «Le Parlement français», en Les parlements aujourd'hui, en: Les cahiers français, 174, 1976, enero-febrero, 21-31.

PARODI, Jean-Luc, Le róle du Parlement dans le systeme politique français. Paris, Association française de Science Politique, 1970.

WAHL, Nicholas, “The French Parliament: from last world to afterthoutt», en, Lawmakers in a changing World, Englewood Cliffs, Prentice Hall, 1966.

\section{Obras de Referencia. BIBLIOGRafias}

Para el estudio de los Parlamentos, de su historia, organización, funciones, proceso legislativo, etc., se cuenta con diversas fuentes de documentación; por un lado, con bibliografías recopiladas por organizaciones parlamentarias, por las Bibliotecas de los Parlamentos y por estudiosos de la materia; y por otro, con diversas obras de referencia en el campo estrictamente parlamentario, y en el más general, de las Ciencias Sociales: fuentes estadísticas, biográficas, diccionarios, bibliografias sociales y económicas, anuarios, guías, índices de abstracts, etc.

Por lo que respecta a las bibliografías, agrupamos aquí tanto las de carácter general como las referentes a los diversos países estudiados, por considerar de mayor utilidad su inclusión en este epígrafe.

La Bibliografia General:

La Unión Interparlamentaria, a través de su Centro Internacional de Documentación parlamentaria, en Ginebra, publica periódicamente Liste d'oeuvrages et articles catalogués, Généve, $1979, \mathrm{n}^{\circ} 1$ y ss. (Recoge la bibliografía de la Biblioteca del Centro de Documentación: obras de referencia, estudios generales y comparativos y monografías por paises; aparece la descripción bibliográfica completa en los estudios comparativos, mientras que bajo cada país las referencias son completas cuando el trabajo se refiere exclusivamente a ese país o sólo describe autor y título, remitiendo a la referencia completa cuando forma parte de un estudio más general). Y una amplia biblografía:

- World-Wide Bibliography on Parliaments. Généve, 1978-1980. 2 v. Contiene: I. 1945 a 1976; II 1977 a 1979. (En el primer volumen clasifica 4.600 trabajos referentes a 133 países. La bibliografía comprende tres partes:

a) Un índice general por países, clasificados por orden alfabético de su nombre en inglés (comprende un cuadro de correspondencia francés-inglés de los nombres de estos países). Este indice se compone de indicaciones bibliográficas completas por cada una de las 4.600 de las que 263, colocadas al comienzo, conciernen a estudios comparativos y generales. 
b) Un índice analítico en el que todas las referencias están clasificadas en 16 secciones, recogiendo todos los aspectos de derecho y trabajos parlamentarios. Bajo cada sección las referencias vuelven a estar clasificadas por países. En este índice la descripción bibliográfica comprende solamente: autor, título, año de publicación y paginación. Un número indicativo reenvía al número en el que se puede encontrar la descripción bibliográfica completa.

c) Un índice de autores que reenvia igualmente al índice general. En el segundo volumen se encuentra más de 2.850 libros y artículos concernientes a 146 países. Se sigue el mismo sistema de clasificación que en el primer volumen. En su mayoria, estas obras pueden ser consultadas en la Biblioteca del CIDP. (Las que no dispone la Biblioteca, pero que presentan un interés suficiente para ser incluidas en la bibliografía, están señaladas con un asterisco en el índice general.)

\section{Otras Bibliografias Generales:}

ELIZALDE JOSE, «Repertorio bibliográfico sobre parlamentos», publicados en la Revista de Derecho Político de la Universidad de Educación a Distancia, Madrid número, 9 y 10,1981. Según indica el propio autor, se han seleccionado obras que ofrecen amplias bibliografías, referencias donde ampliar el conocimiento de aspectos específicos, épocas, paises e instituciones concretas. El criterio de clasificación facilita la búsqueda de la información:

I. Fuentes y referencias generales (fuentes históricas seleccionadas y guias sobre fuentes, obras generales y bibliográficas, diccionarios y estudios comparativos; publicaciones de Centros de Documentación e Investigación parlamentaria).

II. Trabajos históricos (estudios históricos generales; Parlamentos medievales; parlamentos en el Estado Moderno; Parlamentos a comienzos de la Edad Contemporánea).

III. Teoría política de la representación (obras generales sobre historia y teoria de la representación; historia de la representación política; teorías contemporáneas de la representación; Estatuto de los parlamentarios; partidos, grupos de presión y Parlamentos).

IV. El funcionamiento de los outputs parlamentarios (reglamentos y procedimientos: El Derecho parlamentario; comportamiento político de los parlamentarios; relaciones Gobierno-Parlamento; proceso legislativo; funciones del Parlamento).

V. Los Parlamentos en sus respectivos sistemas políticos (teoría general del régimen parlamentario; Asambleas parlamentarias supranacionales, Asambleas parlamentarias de Estados Federales y Comunidades autónomas).

HAGER, Cross-national legislative Institutions, Processes and Behavior: A Bibliography. Nortolk, Old Dominion University, 1974.

Dauven-Cattelain, Marléne. "Etudes Universitaires sur le Parlement Européen. (Bibliographie)». En Res Publica, (1)1979, 171-180. Comprende tesis doc- 
torales e investigaciones universitarias terminadas o en preparación, clasificadas por secciones. Se completa con dos índices: nombres de autores y directores de investigación y Facultades o centros universitarios que permiten ponerse en contacto con los mismos para cualquier información.

Otras fuentes de Análisis Bibliograficos Criticos:

MELLER, Norman, "Legislative Behavior Research", en, The Western political quarterly, 13 (1), 1960, 131-153.

WAHLKE, John C., "Behavioral analyses of representative bodies, en RANNEY, Austin, Essays on the behavioral study of politics, Urbana, University of Illinois Press, 1962.

MELLER, Norman, "Legislative behavior research revisioned: a review of five years publications», en, The Western political quarterly, 18 (4), 1965, 776-793.

PATtERSON, Samuel C., "Comparative legislative behavior: a review essay", en. Midwest journal of political science, (12) 1968, 599-616.

PATterson, Samuel C., "Trends and prospects in legislative behavior research", en, Comparative behavior: frontiers of research. Samuel C. Patterson and J. C. Wahlke. London, 1972.

PATterson, Samuel C., The British House of Commons as a focus for political research. Comparative legislative research center, reprint series n. ${ }^{\circ} 3$. University of lowa, Departament of Political Science.

MEZEY, Michael L., "Comparative legislative studies newsletter», en Legislative studies quarterly, 1 (2) 1976, 269-282.

JEWELL, Malcolm F., "Legislative studies in Western democracies: a comparative perspective", en, Legislative studies quarterly, 3 (4), 1978, 537-554.

Con anterioridad a que el Centro Internacional de Documentación Parlamentaria, de Unión Interparlamentaria, publicara World-Wide Bibliography on parliaments (recogiendo la bibliografía parlamentaria desde 1945, de 133 paises) las referencias bibliográficas sobre Parlamentos se encontraban incluidas dentro de las bibliografías nacionales y jurídicas de cada país y recogidas por las Bibliotecas de los respectivos Parlamentos o publicaciones de las Cámaras, como es el caso de España en su Boletín de Información Bibliográfica y Parlamentaria de España y del Extranjero, cuyo contenido hemos descrito en el capítulo referido a España.

En Francia, A. GRANDIN, Bibliographie générale des Sciences juridiques, politiques, economiques et sociaux de 1800 à 1926. Paris, Recueil Sirey, 1926$1931.5 \mathrm{v}$.

En Alemania, EDWIN M. BORCHARD, Guide to the law and legal literature of germany... Washington, Government Printing Office, 1912.

También puede localizarse bibliografía en tratados y manuales de Derecho parlamentario del siglo $\mathrm{XIX}$ y $\mathrm{XX}$, asi como en monografías sobre los distintos Parlamentos.

Para conocer los estudios históricos en este tema, algunos Parlamentos, como el de Gran Bretaña, han comenzado la tarea de una bibliografía retrospectiva referida a su país. Esta tarea también se está llevando a cabo por Centros de Documentación y Organizaciones Internacionales Parlamentarias. 
De las bibliografias por países destacamos:

\section{ALEMANIA}

AlemanIA (R.D.) Volkskammer. Die Volkskammer der DDR. 7 Whalperiode. Berlin, 1977.

Alemania (R.F.). Deutscher Bundestag. Die Mitglieder des Deutschen Bundestages. 1-8. Wahlperiode. Alphabetisches Gesamtverzeichmisstand: Bonn, 1979. (Materialien).

AscHL, A. J., Staats-und Verfassungsrechtlichen lexicum. Bochum, Falkner verlag, 1976.

BermbaCH, Comp., Hamburger Bibliographie zum parlamentarischen system der Bundesrepublik Deutschand 1945-1970. Opladen, 1973.

DIEDERECH, N., Wahlstatistik in Deutschland. Bibliographie der deutschen Wahlstatistik, 1848-1975. München, verlag documentation, 1976.

SCHINDLER, 30 Jahre Deutschen Bundestag-Dokumentation, Statistik, Daten. Bonn, 1979.

\section{FRANCIA}

HeINZ, Grete, The French Fifth Republic, establishment and consolidation (19581965). An annotaded bibliography. Standford, Hoover Institution Press, 1970.

HeInZ, Grete, The French Fifth Republic: continuity and change, 1966-1970. An annotated bibliography. G. Hein and Agnes F. Peterson. Stanford, Hoover Institution Press, 1974.

DEUTSCH-FranzÖSISCHES INSTITUT, Ludwigsburg, La France contemporaine. Guide bibliographique et thématique, sous la direction de $\mathrm{R}$. Lasserre. Tübingen, .M. Niemeyer, 1978.

TravauX inedits de science politique. Liste de theses, mémoires et diplomes soutenus en France de 1959 á 1962. Paris, Fondation nationale de sciences politiques, 1963.

Cours et travaux inédits de science politique. (Reseña de trabajos inéditos efectuada y publicada cada año en la Revue Française de Sciences Politiques, desde el año 1963.

\section{Gran Bretaña}

BARKER, Anthony, “Parliamentary Studies, 1961-1965: A Bibliography and Comment». En Politica/ Quarterly, 36/1965, julio, 347-359. 
BOARDMAN, Robert, Britain and the International systems, 1945-1973: A Guide to the literature. Halifax: Center for Foreing Policy Studies, Dalhousie University, 1974, $159 \mathrm{p}$.

Chrimes, S. B., and Roots, I. A., English Constitutional History: A Select Bibliography. London, Routledge and Paul, 1958, $38 \mathrm{p}$.

CoBb, Henry S., A Handlist of Articles in Periodicals and Other Serial Publications Relating to the History of Parliament. London, House of Lords Record Office, 1973, $82 \mathrm{p}$.

Cook, Chris, Sources in British Political History, 1900-1951. London, Macmillan, $1975,5 \mathrm{v}$.

GOEHLERT, Robert V., and FEWTON, S. Martin, The Parliament of Great Britain: $A$ Bibliography. Lexington, D. C. Heath, 1983 (Lexington Books), 209 p. Esta bibliografía recoge fuentes de información bibliográfica sobre el Parlamento inglés, y el material publicado en inglés de los últimos cien años. Esta Compilación cubre la historia, desarrollo y proceso legislativo del Parlamento, con la siguiente clasificación sistemática: Origenes y desarrollo del Parlamento; proceso legislativo; Cámara de los Comunes; Cámara de los Lores; Organización del Parlamento; Parlamento y electorado; Miembros del Parlamento y Servicios de apoyo al Parlamento. Incluye en addendum los materiales publicados en el último año y medio, y las tesis británicas desde 1950. Se completa con un índice de autores y de materias.

HYLAND, Henry Stanley, King and Parliament; $\bar{A}$ Selected List of Books. London, Cambridge University Press, 1951, $32 \mathrm{p}$.

PALMER, John, Government and Parliament in Britain: A Bibliography 2d. ed. London, Hansard Society, 1964, $51 \mathrm{p}$.

RuSCH, M., «Parliament and Government. An annoted bibliography of Government publications for the 1977-78 Parliamentary session». En Parliamentary Affairs, n. ${ }^{\circ} 4,1979,482-493$.

Seymour-Ure, Colin, "Bibliography on British Central Government and Politics". En English Constitution, edited by W., Bagehot, pág. 311-353. London, Watts, 1964.

SLOAN, R. D., Comp., Reapportionment Bibliography, 1969-1979. Colorado, University of Colorado at Boutler-Bureau fo Governmental Research and Service, 1979. Recoge bibliografia de la historia del Parlamento británico del período 1969-1979.

Otras fuentes Bibliograficas Sobre el Parlamento Británico:

Anderson, Ian G., ed., Councils, Committees and Boards: A Handbook of Advisory, Consultative, Executive and similar Bodies in British Publis Life. Beckenham: CBD Research, 1977. 402 p. 
Woods, Comp; A Bibliography of Parliamentary Debates of Great Britain. London, 1956.

TIMES Guide to the House of Commons. 1979. London, Times Books, 1979.

ITALIA

ItAliA. Camera dei deputati. Annuario Parlamentare. 1978 y ss. Quaderni di Documentazione del Servicio Studi (materiale di documentazione sulla situazione in Italia; Diritto comparato).

ITALIA. Senato; (Bibliografías publicadas por la Biblioteca).

De las Enciclopedias y Diccionarios Parlamentarios destacamos:

Abranham, L. M., A parliamentary Dictionary, by L. M. Abraham and S. C. Hawtrey. London, Butterworth, 1956. Define y explica expresiones, tanto coloquiales como técnicas, utilizadas en las Cámaras del Parlamento británico. No proporciona referencias de los otros estamentos gubernamentales, aconsejando para ello el uso de Erskine May's, Parliamentary practice.

EgBer, Lawrence Deems, Multilingual Law dictionary; english-francais-españolDeustsch. By Lawrence Deems and F. Morales-Macedo. Aphen ann den Rijn, Sijthoff, 1979. Ofrece en español, francés y alemán equivalentes de términos jurídicos y expresiones afines que se usan en idioma cuando los conceptos de dichos términos son idénticos o similares. Si no existe equivalente, da una explicación sucinta de su significación en cada uno de esos idiomas. Como complemento, incluyen cuatro anexos (definición en inglés de los términos; lista de algunos diccionarios jurídicos; guía sobre Derecho y las publicaciones de distintos países, tales como: el Annual Legal Bibliography, Bibliography on Foreing and Comparative Law, etc.; lista de los países miembros de las Naciones Unidas; lista de los organismos de N. U. y entidades afiliadas).

GIL RoBles y QUIÑONES, José María, Diccionario de Términos electorales y parlamentarios, por José María Gil Robles y Quiñones y Nicolás Pérez-Serrano. Madrid, Taurus, 1977. Se estudian términos electorales y aspectos relevantes de la organización interna y funcionamiento del Parlamento en España. Con una doble perspectiva: la normativa actual y referencia a la práctica del parlamentarismo español. Remite en cada voz a los artículos de los Reglamentos desde 1810 a 1971. Se completa con una serie de concordancias con otros términos que están en relación y que amplian conocimientos del término objeto de estudio.

HAWTREY and BARCAY, A parliamentary Dictionary, 3. ${ }^{a}$ ed. London, 1974.

PALLOTTA, Diccionario político e parlamentare italiano. Roma, 1976.

Parlamento Europeo, Direction de la traduction et de la terminologie. Formules parlementaires. Luxemburg, 1972.

Winding, Norman, An Enciclopaedia of Parliament, by N. Winding and Philip Laundy. London, Cassel, 1974. 
Parlamento Europeo, Formules parlementaries. Luxemburg, 1971. (Texto en inglés, francés, italiano y alemán).

Parlamento Europeo, Terminologie du Réglement du Parlement Européen. Luxemburg, 1973. (Texto en inglés, francés, italiano, alemán, holandés).

Otros diccionarios se reseñan bajo cada país en el epigrafe "Otros Materiales". No recogemos aquí los numerosos diccionarios de Derecho y Ciencias Sociales en los que se encuentran referencias parlamentarias, por razones de espacio.

De las obras de referencia sobre Parlamentos destacamos aquí sólo algunas de carácter general; las específicas de cada país las hemos incluido dentro del epígrafe "Otros Materiales», bajo el país objeto de estudio.

GUIAS

La Unión Interparlamentaria publica:

- World directory of Parliaments. Généve, 1979 y ss.

Comprende 134 países. Los países están clasificados en el orden alfabético de su nombre en inglés, encontrándose un cuadro de correspondencia francés-inglés.

Da a conocer de cada país los siguientes datos:

1. Nombre oficial de las dos Cámaras en conjunto (para el caso de los Parlamentos bicamerales).

2. Si es mono o bicameral.

3. De cada Cámara describe:

- Número de miembros.

- Duración de la legislatura.

- Fecha de las últimas elecciones parciales.

- Dirección.

- Teléfono.

- Dirección telegráfica y télex.

Por último, indica la persona, cargo y dirección de cada uno de los Parlamentos a quien dirigirse para solicitar información concerniente a las actividades legislativas de cualquiera de las Cámaras.

- DIRECTORY for echange and communication of parliamentary information. Genéve, 1979.

\section{GUIAS DE DOCUMENTOS}

El campo de las publicaciones oficiales está cada día más estudiado. La IFLA (International Federation of Library Associations) comprende una sección de 
"Official Publications", que recoge las publicaciones oficiales de numerosos paises.

Muy útil es la revista especializada, Government publications Review. An international journal of issues and information Resources. (Estados Unidos. Bimensual.) Recoge estudios de publicaciones oficiales y reseña cuantos trabajos y guias se publican sobre el tema.

Un ejemplo de estas guías

- Cherns, J. J., Official Publishing: An Overview. An International Survey and Review of the Role, Organisation and principles of Official Publishing. Oxford, Pergamon Press, 1979. 527 págs. (estructurada en tres partes: En la parte I expone el campo y la importancia de las publicaciones oficiales; en la II analiza las publicaciones del Gobierno y organizaciones intermedias de 20 países y estudia el origen y funciones de HMSO británica, y, finalmente, en la III se ocupa del estudio sobre el acceso a la información oficial; el control de las publicaciones oficiales; centros de información; "Reports of Parlamentary proceedings", etc).

Otras obras de referencia que proporcionan datos sobre Parlamentos son los Annuarios políticos, entre ellos:

- Banks, Arthur S. and Overstreet, William, eds., Political handbook of the World, 1980. New York, MacgrawHill Book Company, 1980. Continúa el estilo de Political Handbook of Europe, publicado desde 1927. Incorpora todos los acontecimientos ocurridos durante el año de publicación. Los cambios en los nombres de los países se indican por medio de "Cross-Referenced" en el índice. Comprende tres partes: I. Gobierno (ordenados alfabéticamente los paises). II. Regiones (por continentes), y III. Organizaciones intergubernamentales (alfabéticamente y dentro de cada una de ellas las instituciones que dependan de las mismas). Los datos sobre el Parlamento de cada país los describe dentro de la Sección 1. ${ }^{\mathrm{a}}$, después de indicar el status político, Presidente del Gobierno, Gobierno y políticos, partidos políticos. Bajo el epígrafe: "Legislatura", da los siguientes datos: sistema bicameral o unicameral, nombres de las Cámaras, número de miembros en cada una de ellas, duración o mandato, distribución de los escaños y Presidente.

- EUROPEA YEAR BOOK. A World Survey. London, Europa publications, 19...

- Mallory, Comp., Political Handbook and Atlas of the World: Parliaments, parties and Press, 1966 y ss. New York, Council on Foreing Relations, 1967. Recoge por años la composición del Parlamento y representación de los partidos y fechas de elección, etc., las fuentes de información para recoger datos son oficiales y privadas. 


\section{Estudios Comparativos y Tratados Generales}

Trabajos comparados sobre Parlamentos pueden consultarse:

AMELLen, M., Parlements. Un étude comparative sur la structure et le fonctionnement des institutions répresentatives dans 55 pays. Paris. Presses Universitaires de France, 1966.

ANDERSON, Lee F., Legislative roll-call analysis. Evanston, Nortwestern University Press, 1966, $206 \mathrm{p}$.

Association française de Science Politidue, Paris, Le role des parlements dans les'démocracies modernes de type libéral. Paris, 1970. (Mecanografiado).

BAAKLINI, A. I., Ed. Comparative legislative reforms and innovations. By A. I. Baakline and James J. Hearphey. Albany, N. Y., State University of New York, $1977,353 \mathrm{p}$.

BeYME, Klaus von, Die Parlamentarischen Regierungssysteme in Europe. München, R. Piper, 1970.

BRENCHON-MOULENES, Christine. Les régimes legislatifs de responabilité publique. Paris, LGDJ, 1974. (Contiene disposiciones legislativas heterogéneas destinadas a reglamentar casos particulares. Describe la estructura de los mismos y la tipificación. Comprende además una bibliografía dividida en dos partes: obras generales y regímenes particulares).

BLondel, J., Comparative legislatures. Englewood Cliffs, N. Y. Prentice-Hall, 1973, $173 \mathrm{p}$.

BOUCHER, Comp., Les parlements d'aujourd'hui. Paris, 1977.

BorToN, Comp., Legislative systems in Developing Countries. Durham, N. C., 1975.

CompION, Gilbert Francis Montrion, and LIDDERDALE, D.W.S., European Parliamentary Procedure, London, Allen und Unwin, 1953.

COLLIARD, Jean-Claude, Les régimen parlementaires contemporains. Paris, Presses de la Fondation Nationale des Sciences Politiques, 1978, $368 \mathrm{p}$.

CHEROT, J. Y., Le comportement parlementaire. Thèse pour le doctorat d'Etat en Droit, Université de Droit, d'Economie et des Sciences d'Aix-Marseille, 1980.

Grumm, A., Paradigm for the comparative analysis of legislative systems. Beverly Hills, Cal., 1973, $83 \mathrm{p}$.

HiRSCH, Comp. Comparative legislative systems. A. Reader in theory and Research. New York, 1971, $470 \mathrm{p}$.

International Commission for the History of Representative and ParliamenTARY InSTITUTIONS, Representative Institutions in theory and practice..., 1970. 
Kornberg, A. Comp., Legislatures in Developmental Perspective. Durham, Duke University Press, 1970, $590 \mathrm{p}$.

Kornberg, A. Comp., Legislatures in comparative Perspective. New York, David MacKay, 1973, 455 p.

Lalumiere, Pierre, Les règimes parlementaires européennes. 2. ${ }^{a}$ ed. Paris, Presses Universitaires de France, 1978.

LEES, J. D. ed., Committees in legislatures: A Comparative Analysis. London, Martin Roberts, 1980, pág. 449 (Estudian: U.S.A., Alemania [R.F.], Canadá, Gran Bretaña, Italia, Japón y Filipinas).

Loewenberg, Comp., Modern Parliaments, Change or Decline. Chicago, AldineAtherton, 1971.

Loewenberg, G., Comparing legislatures. By G. Loewenberg and S. C. Patterson. Little, Brown, 1979.

LUCIFREDI, P. G., La titolaritá dell'iniziativa legislativa: varie forme di iniziativa nel diritto comparato. Milano, Giuffré.

MEZEY, M. L., Comparative legislatures. London, Duke University Press, 1979, 317 p.

OLson, D. M., Legislature process: A comparative Aproach. London, Harper and Row, 1980.430 p. (Es más bien un libro de texto que un trabajo teórico. Contiene material organizado sobre elecciones, representación, partidos, grupos parlamentarios, comisiones, sesiones plenarias, etc.).

PAtTerson, S. C., Comparative legislative behavior: parties of research. New York, Wiley, 1972, $311 \mathrm{p}$.

Paxton, John, Comp., World legislatures. London, Macmillan, 1974, 169 p.

Rausch, Heinz, Zur theorie und Geschichte der Repräsentativersfassung. Darmstadt, Wissenschaftliche Buchgesellschaft, 1968, 554 p.

SMITH, J., ed., Legislatures in Development: Dynamics of change in New and old States. London, Duke University Press, 1979, 407 p. (Sobre España, Kenya, Tanzania, Chile, India, Malasia, Tailandia, etc.).

Union InTERPARLAmentaire, Généve, ed. Les Parlements dans le monde. Recueil de données comparatives. Préparé par Valentine Herman et François Mendel. Paris, Presses Universitaires de France, 1977, 883 p. (Existe otra edición de Hansard Society de Londres, en 1962, 321 p. Describe 56 Parlamentos, el estado de las instituciones hasta $1 .^{\circ}$ de sept. de 1974.

En 70 cuadros comparativos, presenta datos de base o estadísticos relativos a los diversos aspectos de la organización, procedimiento o actividades de los parlamentos descritos.

Tienen gran utilidad porque permiten constatar rápidamente las similitudes y las diferencias esenciales entre los sistemas sobre una cuestión dada. La materia de cada uno de estos cuadros está igualmente tratada en un texto que cuenta o explica los datos presentados en el cuadro.

Recoge todas las cuestiones relativas a: a) La composición del Parlamento (características del Parlamento, derecho de voto, etc.). b) Organización y funcionamiento (disposición de la Cámara, autonomía reglamentaria, etc.) 
c) Función legislativa (iniciativa), etapas, etc. d) Competencia presupuestaria.

e) Control del Ejecutivo. f) Otras funciones del Parlamento.

Finalmente aporta una bibliografía selectiva, breve (por países).

WHEARE. Legislatures, $2 .^{\circ} \mathrm{ed}$. London, 1968.

Desde un punto de vista jurídico existen publicaciones periódicas de estudios comparativos: Informations Constitutionnelles et parlementaires publicada por la Asociación de Secretarios Generales de los Parlamentos, en Ginebra, de periodicidad trimestral. Unión Interparlementaire publica, Chronique des élections parlementaires, de periodicidad anual desde 1967; contiene una sección titulada "Evolución parlamentaria en el mundo".

Estudios Comparados Sobre Bicameralismo, Monocameralismo:

UNIVERSIDAD CENTRAL DE VENEZUELA. Las funciones de los modernos Parlamentos bicamerales. Caracas, 1971. (Describe los siguientes paises: Afganistán, Argentina, Australia, Austria, Barbados, Bélgica, Bolivia, Brasil, Camboya, Canadá, Ceilán, Colombia, Checoslovaquia, Chile, Ecuador, EE.UU., Etiopia, Filipinas, Francia, Gran Bretaña, Holanda, India, Irán, Irlanda, Islandia, Marruecos, México, Nicaragua, Noruega, Perú, Portugal, República Dominicana, Alemania (R.F.), Suecia, Suiza, Turquía, URSS, Uruguay, Venezuela, Vietnam, Yugoslavia. En la bibliografía dedica una parte a textos constitucionales y legales, facilitando la localización de las Constituciones de los países que estudia).

TRIVELLI, Laurent: Le bicamérisme. Institutions comparées. Etude historique, statistique et critique des rapprots entre le Conseil National et le Conseil des Etats. Lausanne, Diffusion Payot, 1975, 534 p. (Estudia en una primera parte: Teoría general del bicameralismo y aplicaciones prácticas. Analiza el bicameralismo en los Estados federativos (EE.UU., Alemania Federal...); Estados Europeos de tipo unitario (Bélgica, Francia; Italia); Estados Escandinavos (Finlandia, Noruega...); Democracias Populares (Unión Soviética, Checoslovaquia, Yugoslavia); Países en vías de desarrollo. En una 2. ${ }^{a}$ parte: La génesis y evolución de las instituciones parlamentarias suizas: Constitucion Federal de 1948; Asamblea Federal después de 1848; las instituciones (Consejo Nacional, Asamblea Federal). Finalmente el estudio de 20 casos particulares suizos (desde 1946-1973): composición de la Asamblea Federal desde 1946; reforma de finanzas federales; ley federal facilitando el derecho de voto en materia federal; Decreto constitucional sobre la protección civil; ratificación de la Convención de la O.I.T. sobre la igualdad entre hombres y mujeres).

\section{ORganizaciones INTERnacionales Parlamentarias}

Enumeraremos a continuación las principales asociaciones y organizaciones internacionales parlamentarias, indicando sus fines, con objeto de completar este trabajo de materiales para el estudio de los Parlamentos:

- American Entrepise Institute for Public Policy Research. Washington. 
Publica desde 1974 volúmenes de análisis electorales y parlamentarios sobre los países democráticos.

- Association Internationale des Parlementaires de langue française. (A.I.P.L.F.).

Se crea el 18 de marzo de 1967 en Luxemburgo. Su fin es animar todas las actividades parlamentarias, tratando de extender la esfera de influencia de la lengua francesa a los países que son completa o parcialmente francófonos; establecer una cooperación estrecha entre los parlamentarios miembros a fin de reforzar la solidaridad mutua que el uso de la lengua francesa ha creado entre ellos.

- Association parlementaire pour la cooperation euro-árabe.

Se crea en mayo de 1974 en París, para promover la cooperación entre Europa y el mundo árabe.

- Association des Secretaires Géneraux des Parlements. Généve. mentaires.

Publica sus informes en la Revista Informations Constitutionnelles et Parle-

- British Group Inter-Parliamentary Union.

- Committee of Co-operation for European Parliamentary Studies. London.

- Commonwealth Parliamentary Association.

Creado en 1911, con el nombre de Empire Parliamentary Association y compuesto de miembros del Parlamento del Reino Unido y sus dominios. Tiene por objeto favorecer las relaciones más estrechas entre la representación parlamentaria de los paises de la Commonwealt. reuniones.

Publicaciones: The Parliamentariam (trimestral); Actas de conferencias y

- Conference de présidents des parlements du Commonwealth.

Se crea en 1969 en Ottawa, Canada, para contribuir a que «Speakers» y Presidentes discutan sobre materia del procedimiento parlamentario, responsabilidades de la Presidencia, etc. Publica los trabajos de las Conferencias.

\section{- Conseil Interparlementaire Consultatif Benelux.}

Su origen: en noviembre de 1955, en Bruselas. Es un órgano consultivo para todos los problemas relativos a la Unión Económica del Benelux; contribuye a la cooperation entre los tres países miembros en lo cultural, política exterior y unificación del derecho.

\section{- Conseil Parlementaire du Mouvement Européen.}

Se crea en 1952 por fusión de la Unión Parlementaire europeenne con el Groupe Parlementaire International du Movement Européen.

- International Commission for the History de representative and Parliamentary Institution. 
Publica la más amplia colección de investigación histórica.

- Hansard Society for Parliamentary Government.

Se crea en agosto de 1944 en Londres, bajo el nombre de Hansard Society. Tiende a promover el gobierno parlamentario en el mundo entero. Publica Parliamentary Affairs (trimestral); libros; informes, etc.

\section{- Parlement Européen.}

Tiene su origen el 19-21 de marzo de 1953 en Strasbourg. Reemplaza y prolonga la "Assemblée Commune" de la CECA. Ejerce poderes de consulta "vis-à-vis» del Conseil y controla la Comisión de las Comunidades Europeas (CECA; CEE y EURATOM). Tiene, además, ciertos poderes presupuestarios, derecho de ser consultado e informado, sobre todo en materia de legislación y de acuerdos comerciales.

Publica: Rapports Parlementaires; Procés-Verbaux; Debats; Recueils de documentation; PE-Information. Etudes et recherches documentaires.

\section{- Union Interparlamentaria.}

Tiene su origen el $\mathbf{3 0}$ de junio de 1889 en Paris. Tiene como objeto favorecer los contactos personales entre los miembros de todos los Parlamentos y promover una acción común para reforzar el desarrollo de las instituciones representativas y la cooperación internacional.

Publica: Bulletin Interparlementaire (trimestral). Es el órgano oficial. Informations Constitutionnelles et Parlementaires (trimestral); Comptes rendus de la Conference (anual); Parlements, étude comparative sur la structure et le fonctionnement des institutions representatives; Problèmes actuels du Parlement, symposium international.

\section{- Centre International de Documentation Parlementaire.}

Tiene su origen en 1965, como departamento del Secretariado de la Unión Interparlamentaria. Su objeto es recoger sistemáticamente la información de las Asambleas legislativas de todos los Estados independientes; difundir esta información; promover la investigación, estudios comparados, etc.

Publicaciones: Chronicle of Parliamentary Elections (desde 1967 anual); Raports and Documents (de periodicidad irregular dentro de esta serie publicó la bibliografía sobre Parlamentos citada en capitulo de bibliografias); Parliaments of the World, 1976, 1977.

\section{- Centre Européen de Recherche et de Documentation Parlemen- taires.}

Creado en 1977, por acuerdo tomado por la Conferencia de Presidentes de las Asambleas parlamentarias europeas, reunida en Viena.

Organiza grupos de trabajo: «Microformas», «Informática». Tiende a favorecer los contactos documentales entre los Parlamentos mediante el sistema CELEX (está en estudio un manual de «Logiciens" realizados o utilizados en los Parlamentos nacionales con vistas a un cambio o adaptación de estos "logiciens" entre los Parlamentos). 
Da a conocer las publicaciones de los Parlamentos nacionales; estudios de investigación y documentación de documentos y publicaciones de la Unión Interparlamentaria.

- World Constitution and Parliament Association.

Creado en 1960 en Estados Unidos. Entre sus actividades, reuniones del Emergency Council of World Trustees, que puede promulgar decretos en situaciones de conflictos y crisis mundiales.

Este Council está llamado a ser reemplazado por un Gobierno Mundial Provisional, de ahí que su finalidad sea reunir un Parlamento Mundial.

Publica: Across Frontiers (de aparición irregular); Draft of a Constitution for the Federation of Earth. 